\title{
O DIÁRIO DE AULA COMO UM ESPAÇO PARA (AUTO)NARRATIVA DENTRO DE AULAS DE CANTO CORAL EM UM PROJETO SOCIAL
}

\author{
Helena Doris Sala ${ }^{1}$
} Ana Lúcia Louro ${ }^{2}$

\begin{abstract}
Resumo
Este artigo apresenta uma reflexão sobre o ensino de música, destacando questões relacionadas a projetos sociais e canto coral. Nele, a educadora musical narra seus dilemas como professora de canto coral para adolescentes, escritos entre abril de 2010 e dezembro de 2012, em um projeto social, tendo como metodologia a "autonarrativa" e "narrativas de si" (OLIVEIRA, 2009), ambas refletidas nos diários de aula (ZABALZA, 2004). O trabalho objetiva investigar sobre a atuação do professor e os caminhos destes, em sua docência, utilizando da ferramenta dos diários de aula como um espaço para a "escrita de si" e "narrativa de si", promovendo reflexões a fim de compreender e modificar suas práticas e com isso moldar a sua identidade profissional. Também analisa os conflitos que ocorrem na prática em projetos sociais (KATER, 2004; KLEBER, 2006, 2008;); problematiza a prática de canto coral (AMATO, 2007; TEIXEIRA, 2008); narra situações de aula, focalizando identidades profissionais envolvidas na mudança de práticas para a conquista de adolescentes percussionistas à aula de canto coral.
\end{abstract}

Palavras-chave: Educação Musical; Projeto social; Canto coral; Narrativas de si. Autobiografia

\footnotetext{
${ }^{1}$ Mestranda em Ciências da Educação pela Faculdade de Psicologia e Ciências da Educação da Universidade do Porto, Graduada em Música pela Universidade Federal de Santa Maria, vinculada a Universidade Federal de Santa Maria através do Grupo de Pesquisa Narramus. Endereço: Rua 13 de Maio, 1199, Centro Ijuí, RS, BR, Cep: 98700000; Telefone: (55) 33321858; Endereço Eletrônico: helenadoris@ hotmail.com.

2 Doutora em Música pela Universidade Federal do Rio Grande do Sul, Brasil, Professora Associada da Universidade Federal de Santa Maria, atuante no Programa de Pós-Graduação em Educação e nos Cursos de Música. Endereço: Universidade Federal de Santa Maria, Avenida Roraima, no 1000 - Camobi - Santa Maria, RS, BR, Cep: 97105-900; Telefone: (55) 99743050; Endereço Eletrônico: analouro@ brturbo.com.br.
} 


\section{INTRODUÇÃO}

No Brasil, são muitos os esforços de pesquisa na área de Música, especificamente, de Educação Musical, destacando-se o trabalho de associações como ANPPOM (Associação Nacional de Pesquisa e Pós-Graduação em Música) e ABEM (Associação Brasileira de Educação Musical). Alguns Programas de Pós-Graduação em Educação também mantêm linhas de pesquisa que contemplam a Educação Musical, como é o caso da linha de Pesquisa Educação e Artes do Programa de Pesquisa em Educação da Universidade Federal de Santa Maria (UFSM). O grupo de pesquisa ao qual está vinculada a investigação, que será relatada neste artigo, tem como referência este programa de pós-graduação simultaneamente ao departamento de música da mesma instituição.

O Grupo de Pesquisa denominado Narramus - Auto-narrativas em Práticas Musicais tem em sua formação pesquisadores professores, alunos da pós-graduação e graduação e colaboradores de duas instituições de ensino superior do Brasil (UFSM e IPA ${ }^{3}$ ) no intuito de possibilitar o debate de suas bases teóricas e práticas, por meio de reflexões. O grupo utiliza a pesquisa (auto)biográfica para problematizar a formação de professores na área da música, bem como estuda, a partir de diversos contextos, como ser e tornar-se professor.

O grupo desenvolve pesquisas biográficas em algumas dimensões, dentre elas, os trabalhos com narrativas de si, autobiografias e narrativas, biografias, memórias, histórias de vida e história oral. Cada trabalho busca uma série de referenciais teóricos que abordam o tema e a especificidade de cada pesquisa. Geralmente, estas pesquisas trabalham com diferentes análises, dentre elas: análise de cartas, diários de aula, e-mails, fotos, entrevistas, questionários, em que o pesquisador torna-se um "pesquisador de si" e visa, por meio de suas próprias vivências e experiências, descrever os dilemas, os caminhos e os desafios de ser um professor de música em diferentes contextos educativos. Possibilitando, por meio de suas reflexões e situações problemáticas, de que maneira o professor pode se instrumentalizar para enfrentá-las. O grupo investiga questões sobre identidades relacionadas com música, através do:

olhar sobre os processos identitários, como foco e não como exclusividade, buscamos refletir sobre os fenômenos da Educação Musical narrados por seus protagonistas. Nesse processo, os discursos verbais e sonoros entrecruzam-se e são

\footnotetext{
${ }^{3}$ Universidade Federal do Rio Grande do Sul.
} 
objeto de um diálogo contrapontístico entre os discursos próprios dos pesquisados, dos pesquisadores e dos autores revisados. Este recorte abstrato se materializa em pesquisas que se utilizam de entrevistas de História Oral Temática e de diários de aula. De qualquer forma, o discurso verbal, em seu entrecruzamento com as sonoridades e as práticas corporais para produzi-las, é o lócus no qual as identidades são moldadas. Tal se dá na "interface", não é o sujeito que tem uma identidade dada, nem o discurso por si mesmo que estabelece a identidade, mas é através de aparatos de subjetivação nos quais o sujeito se contrapõe ao discurso que ele passa a estar ciente de aspectos de sua identidade, dos quais não possui consciência plena anterior ao exercício de falar e escrever. (BORBA, BECK, LOURO, 2012, p. 1).

E a partir dessa visão, o texto a seguir apresenta sua temática relacionada a "autonarrativas" como busca e reflexão sobre a atuação da professora em questão que utiliza a ferramenta dos diários de aula como meio para discussão de sua própria prática. Permeando as subjetividades escritas, o ato de narrar atenta para os aspectos da identidade profissional, a partir dos questionamentos que o professor coloca em jogo sobre sua prática dentro e fora da sala de aula, bem como produz ao professor a possibilidade de reverter e modificar sua docência.

\section{MÉTODOS: COMO ACONTECE A “NARRATIVA DE SI"}

Como membro deste grupo de pesquisa, realizei uma investigação que pretendo descrever neste artigo. Tal investigação, foi realizada dentro de um recorte biográfico de minha monografia de conclusão de curso, a qual assumindo portanto a problematização de minhas vivências pessoais como parte do processo de pesquisa, justificando a escolha da conjugação em primeira pessoa do singular. No entanto, esta pesquisa de monografia aconteceu sob a orientação da professora orientadora como contraponto de leitura e discussão teórica, por isso, apesar de existirem dois autores, o texto é escrito dessa forma.

Desde os primeiros passos, a música está presente em minha vida. Cresci em ambientes permeados por música e sua prática, os quais contribuíram para minha escolha como educadora nessa área. Cantar, tocar violão, participar de eventos e festivais musicais eram minha paixão quando adolescente. Ao pensar no que eu faria ao longo da vida, a opção que escolhi foi ingressar no curso de Licenciatura em Música, pois meu interesse estava em agregar todas as vivências que tive até aquele momento com a possibilidade de aprender a ensinar música.

Daí em diante, dentro da academia de música, procurei me engajar em projetos que estivessem ligados ao canto coral e à educação musical. Iniciei, por meio do Programa 
Nacional Conexões de Saberes, aulas de canto coral em um projeto social e, ao mesmo tempo, comecei a participar de um dos grupos de pesquisa da linha de pesquisa Educação, o qual ofereceu-me subsídios e a possibilidade para iniciar minha trajetória como pesquisadora, e busquei compreender meus conflitos e os desafios com o ensino de música. Seguindo esta linha de pesquisa, questionei-me, a partir da formação como professora de canto coral, de que maneira eu poderia contribuir com o canto coral em um projeto social, cuja ênfase principal é a percussão. Dentro do grupo de pesquisa, fui percebendo a importância de me autonarrar, relatando caminhos enquanto professora; desta maneira, contextualizando minha prática neste espaço.

A perspectiva metodológica da autorreflexão e crítica, escritas por intermédio de “narrativas de si” Eggert (2004), possibilita o estudo dos dilemas e problemáticas vividas pelo professor dentro e fora da sala de aula, por meio de diários de aula (Zabalza, 2004). Souza (2000) defende as teorias do cotidiano que se dispõem a ouvir seus agentes para verificar como ocorrem as atuações em sala de aula, bem como uma reflexão transcendental, ou seja, aquela que proporciona a mudança das práticas e valores nesse nível, promovendo uma nova leitura de mundo:

O saber fenomenológico como análise reflexiva dá lugar eminente ao sujeito, à experiência vivida. Considera que é através da história pessoal, através das suas vivências e experiências que o sujeito vai tomando consciência de si mesmo, do mundo e do outro. (SOUZA, 2000, p. 22).

Souza (2008) analisa o sujeito imerso e envolvido em um aramado de significações culturais as quais servem como aprendizagens em que este sujeito cria sentido e faz um mundo possível. Segundo a autora, quando reconstruímos uma realidade na qual "retomamos experiências e vivências musicais concretas que são vividas pelos alunos fora do cotidiano escolar, o conteúdo da educação musical pode ser repensado e redimensionado" (Souza, 2000, p. 163).

Nogueira (2015) discute que no campo das Ciências da Educação, o empenho pelo universo das "narrativas biográficas educacionais" propagou-se através de estudos realizados "sobre a vida na sala de aula", bem como "os processos de desenvolvimento profissional de professores ao longo da vida", a fim de que o objeto de investigação referenciem "modos de construção de conhecimento". O autor explica: 
$\mathrm{O}$ ato narrativo como experiência de linguagem, é objetivo, assim sendo, de uma configuração do tempo, pré-figurada e re-figurada através da mediação de um tempo figurado, cujos aspectos temporais, no campo prático da experiência do sujeito, constroem e mediam a própria narrativa. (Nogueira, 2015, p. 336)

Segundo Nóvoa, "o esforço de narrar o trabalho pedagógico e de narrar-se como professor definem uma nova identidade profissional" (apud OLIVEIRA, 2009, p. 10), a qual irá contribuir para uma reflexão que ajude a criar novas teorias e práticas. Oliveira (2006) acrescenta que o "narrar-se como cuidado de si" e "narrar saberes para conhecê-los" produzem processos de identificação com sua profissão, pois na medida em que o professor narra suas experiências, ele vai estruturando caminhos e investigando-os, a fim de conhecer suas representações e práticas, instaurando-se um espaço de reflexão no qual ele passa participar de seu processo de formação, tornando-se "pesquisador de si" e de suas trajetórias de vida:

\footnotetext{
Neste movimento, não somente reconstruímos nossas lembranças através do trabalho da memória e do atravessamento do esquecimento, mas potencializamos a possibilidade de refletir sobre modelos, perfis pessoais e profissionais que participam da nossa constituição de professor, ainda, na possibilidade mais radical, viabilizada pela imaginação criadora, (re)inventarmos outras possibilidades redirecionando nossos trajetos pessoais e profissionais. (OLIVEIRA, 2009, p. 22).
}

Partindo deste mesmo olhar subjetivo, a narrativa autobiográfica está presente nesta pesquisa por meio de diários de aula, de acordo com o que é proposto por Zabalza (2004), como um documento pessoal, que torna-se um espaço narrativo dos pensamentos dos professores. Estritamente, o que se pretende explorar por meio do diário é o que nele figura como expressão da versão do professor, mediante a própria atuação e da perspectiva pessoal que o mesmo enfrenta (Zabalza, p. 41). Segundo este autor, esta corrente de orientação qualitativa está sendo seguida com grande destaque nas pesquisas educativas dos últimos tempos. No seu entendimento, os diários de aula desenvolvem-se por meio de duas variáveis: a riqueza informativa e a sistematicidade das observações recolhidas. A primeira realça não apenas registros externos em que os fatos narrados acontecem, mas igualmente os internos e reflexivos na visão do professor, pois contrastam tanto como "objeto-descritivo" quanto "reflexivo-pessoal", possibilitando ao professor um desenvolvimento pessoal; e a segunda variável por ser transitável obtém uma leitura diacrônica sobre os fatos, ou seja, pode-se analisar sua evolução e diferentes caminhos tomados das situações vividas em aula. 
Por meio da escrita de situações/experiências, o diário possui grande importância como elemento de expressão de vivências e sentimentos, e a partir desse narrar o professor tem a possibilidade de analisar e reconstruir seus dilemas vividos em sala de aula. Josso (2004) também defende a narrativa escrita como um processo interior, no qual o sujeito narra seus pensamentos e sentimentos vividos:

\footnotetext{
a narrativa escrita apresenta-se como uma tentativa que oferece acesso a um percurso interior, no qual evolui em conexão a um percurso exterior, nos quais se exprimem sobre dimensões sensíveis, que dão cor ao que foi vivido e experienciado. $\mathrm{O}$ ato de escrever fornece no próprio movimento da sua escrita fatos tangíveis, estados de espírito, sensibilidades, pensamentos a propósito de emoções e sentimentos, bem como atribuições de valores. (JOSSO, 2004, p. 174).
}

Por meio desta metodologia, procurei oportunizar e potencializar vivências com o canto coral em um projeto social, a fim de que outros indivíduos possam sentir a experiência em cantar e fazer parte de um grupo coral. Especificamente neste texto, selecionei para analisar trechos de 7 diários de aulas dos 50 escritos entre o período de abril de 2010 e dezembro de 2012. Neles, faço uma reflexão sobre meus dilemas por meio do trabalho com o canto coral com adolescentes, repertórios, diálogo e a busca por uma identidade profissional. E de antemão destaco a necessidade que tive em rever minha prática de ensino para agregar os alunos à aula de canto coral, visto que é um projeto social em que o eixo principal é a percussão.

\section{DISCUSSÕES: PROJETO SOCIAL E O CANTO CORAL}

$\mathrm{Na}$ contemporaneidade, ocorrem consideráveis propostas de trabalho na área de projetos sociais que, na sua maioria, têm a música como processo educativo, visando modificar a realidade social de crianças, adolescentes e jovens das camadas menos favorecidas econômica e socialmente, e socialmente vulneráveis (KATER, 2004; KLEBER, 2006). Segundo Kleber (2008), cada vez mais se proliferam em ONGs, movimentos sociais organizados e em projetos sociais, práticas musicais voltadas ao trabalho com jovens adolescentes em situação de risco social, e tais ações são campos emergentes que produzem conhecimento sociocultural, visto que atuam na construção formativa dos indivíduos envolvidos nesses grupos.

Kleber corrobora que: 
as práticas musicais nas ONGs se mostram como um fator potencialmente favorável para a transformação social dos grupos de indivíduos, principalmente se considerando os padrões socioculturais nas práticas musicais presentes no cotidiano dos alunos. Poder contar com seus valores musicais no processo pedagógico-musical parece ser um ponto significativo para um trabalho de ampliação do status de "ser músico" ou de participar de um grupo musical. (2008, p. 233).

Educadores da área da música compreendem que, mesmo com a LDB $\mathrm{n}^{\mathrm{o}} 11.769^{4}$ aprovada e fazendo parte da escola, ela também tem função social e está presente em ONGs e projetos sociais. Gradualmente, terá melhor ênfase e conhecimento sobre esse ensino, quando abranger mais camadas, tanto educacionais e sociais quanto políticas.

Outro educador que reflete sobre a atuação em projetos sociais e o papel da educação musical nestes contextos é Carlos Kater (2004), que enfatiza mesmo que ainda, os educadores, não possuir suficientemente ações que orientem seus alunos nas universidades públicas brasileiras a atuarem na atual sociedade, problematiza o papel da educação mediante questionamentos que levam o educador a pensar sobre "Por que realizar um trabalho, uma ação educativa junto a projetos sociais? Qual é de fato sua importância?” (p. 46). E mais, ao responder a essas perguntas, Kater (2004) continua... "Trabalhar quais músicas, para educar quem? Crianças, adultos, idosos, jovens de qual situação socioeconômica e cultural?” (p. 46). $\mathrm{Na}$ busca de meios para o trabalho em ações como estas que promovam a valorização do indivíduo e a reconstrução da nossa trajetória como educadores, Kater (2004) adverte que o educador precisa ter consciência de seu papel dentro de um projeto social, como em qualquer outra profissão:

[...] cada profissão carrega em si uma responsabilidade e um compromisso de desempenho junto à sociedade. Todas elas têm sua razão de ser de acordo com a expectativa de melhor qualidade de vida que prometem aos cidadãos de seu tempo. No caso da educação musical temos tanto a tarefa de desenvolvimento da musicalidade e da formação musical quanto o aprimoramento humano dos cidadãos pela música. (p. 46).

De acordo com Amato (2007), em artigo sobre o canto coral e a prática sociocultural e educativo-musical uma das alternativas para o ensino de música é o canto coral, considerando que

\footnotetext{
${ }^{4}$ A Lei 11.769/08 aprovada em 18/08/2008 altera a Lei de Diretrizes e Bases (LDB) 9.394/96, e estabelece a obrigatoriedade do ensino da música nas escolas de educação básica em até 3 anos.
} 
[...] o coral desvela-se assim como uma extraordinária ferramenta para estabelecer uma densa rede de configurações socioculturais com os elos da valorização da própria individualidade, da individualidade do outro e do respeito das relações interpessoais, em um comprometimento de solidariedade e cooperação. Todas essas interfaces inerentes ao desenvolvimento do trabalho de educação musical em corais contribuem para a inclusão e integração social. (p. 7).

Neste sentido, assim como Amato (2007), acredito que o canto coral pode ser um instrumento que agrega e promove a integração do indivíduo, dando-lhe oportunidade para que possa "aprender arte independentemente das informações que recebeu ou não no seu ambiente sociocultural, familiar ou escolar" (p. 81). Gostaria apenas de contextualizar o canto coral no Brasil, mas não de esgotar essa temática.

Cantar está presente em nossa sociedade muito antes do período medieval, é uma prática que faz parte de uma cultura específica (Campos; Caiado, 2007). O canto coral é visto por muitos educadores como uma ferramenta para a inclusão e valorização de quem canta. Fonterrada (2008) argumenta que o canto coletivo tem estado presente nas manifestações musicais das mais diversas culturas, desde tempos imemorais até os dias de hoje. No Brasil, segundo Campos e Caiado (2007), o canto coral desenvolveu-se no século XVIII, aliado aos serviços religiosos e no século seguinte difundiu-se para os salões aristocráticos da corte portuguesa (no Estado do Rio de Janeiro) e em teatros especificamente para o canto lírico. No século XX, porém, viu-se a necessidade de uma produção artística que expressasse a identidade brasileira.

Campos (2009) afirma que manter um coro custa pouco em relação às outras práticas musicais, mas mais que isso, a importância de cantar está presente na necessidade de se comunicar e compartilhar através da coletividade considerando as várias identidades e interesses dos grupos corais. No Brasil o canto coral também está ligado e sendo desenvolvido a projetos sociais como: Projeto Guri, Associação Meninos do Morumbi, Musicalizar é Viver, entre tantos outros. Neste mesmo sentido, Santos (2005) pondera que "fora da escola, projetos comunitários e sociais têm se dedicado com frequência cada vez maior ao ensino da música, com diferentes ênfases" (p. 32).

Destaco a ausência de abordagens sobre o canto coral em projetos sociais e a relevância desta pesquisa à área da educação musical, como fonte de inspiração para outras pesquisas analisarem como ocorre esse ensino em projetos sociais. Ainda mostrando a visão dos educadores musicais na perspectiva de seus dilemas, desafios e imprevistos, da mesma forma com que relato nesta pesquisa minha experiência como educadora musical neste coral. 


\section{RESULTADOS: ANÁLISE DOS DIÁRIOS DE AULA}

Meus alunos são integrantes de um grupo de percussão que existe há mais de oito anos, com adolescentes na faixa etária entre 10 e 18 anos. O projeto social ${ }^{5}$ inicialmente chamado "Oficina de Percussão Camobi” objetivou ensinar música para estudantes de escolas públicas do bairro de Camobi, localizado na cidade de Santa Maria/RS. Iniciou em fevereiro de 2005. Em 2007, tornou-se a Associação CUICA - Cultura, Inclusão, Cidadania e Artes, constituindo-se à criação de uma $\mathrm{ONG}$, sem fins lucrativos, para a ampliação do projeto. A ONG possuiu durante esses anos algumas outras oficinas, que aconteceram em alguns semestres, de acordo com as pessoas que se achegavam e se interessavam em contribuir suas experiências e habilidades ao projeto, tais como violão, flauta doce, canto coral, violino, gaita. Atualmente, realiza a oficina de construção de instrumentos, porém, o que resume este projeto social é o grupo de Percussão.

O Coral surgiu por meio de uma oficina vinculada ao Programa Nacional de Extensão Conexões de Saberes, realizado pela referida universidade, contando com o apoio da PróReitoria de Extensão. A ação foi uma proposição do Programa LEM: Tocar e Cantar vinculado ao Laboratório de Educação Musical (LEM) e da referida Associação CUICA Cultura, Inclusão, Cidadania e Artes. A ação é constituída de um Programa de Oficinas musicais congregadas no "LEM-CUICA e escolas: lugares compartilhados de ações de educação musical" objetivando desenvolver atividades de educação musical em diferentes espaços. Este programa objetivou promover o "diálogo" entre a universidade e a comunidade de abrangência da universidade. Iniciei as atividades de canto coral e educação musical a partir do fazer musical coletivo por meio de ensaios, com o objetivo de promover o desenvolvimento músico-vocal de adolescentes e adultos da comunidade referida, propiciar "diálogos" entre a universidade e a comunidade e realizar apresentações em diferentes contextos. Acreditando que a inserção da universidade em projetos sociais por meio de ações com licenciandos em música, nestas situações de ensino, possa contribuir para o desenvolvimento de vivências corais dos alunos envolvidos em projetos sociais.

\footnotetext{
5 Entre a coleta de dados e a escrita da monografia que vem dar forma a este artigo, ocorreu a construção da dissertação de mestrado de um dos idealizadores do referido projeto social. Sugiro leitura em Rozzini, José. E. S. Educação musical na CUICA: percussões e repercussões de um projeto social. Dissertação (Mestrado em Educação) - Universidade Federal de Santa Maria, Santa Maria, RS, 2012.
} 
O primeiro ensaio do coral iniciou em abril de 2010 e o último em dezembro de 2012. Nos dois primeiros anos os ensaios ocorriam uma vez por semana, com duração de uma hora e meia. A partir de 2012, ocorriam quinzenalmente, com aulas seguidas em dois dias e com a mesma duração. Na condição de regente educadora de canto coral, propus atividades vocais referentes à afinação, colocação vocal, postura vocal e articulação, visando um trabalho gradual, a fim de que conseguissem, afinadamente, dentro das condições vocais do grupo, entoar os vocalizes ${ }^{6}$, melodias e o repertório. Muitos adolescentes, principalmente os meninos, nesta faixa etária, estão mudando de voz, e, com isso, apresentam maior dificuldade para cantar, além de timidez mais acentuada.

\begin{abstract}
Nos primeiros ensaios será comum alguns acharem engraçado os exercícios de aquecimento vocal, por acharem um pouco estranho e ficarem com vergonha para entoar cada vocalize. Neste ensaio notei que eles estavam muito tímidos, alguns só me observavam e não respondiam ao que eu perguntava, outros já riam para qualquer coisa que eu demonstrava, tirando aqueles que não queriam fazer nada (DIÁRIO 31.05.2010).
\end{abstract}

Antes de falar sobre aspectos musicais, ressalto outros fatores que podem interferir no sucesso de um ensaio, pois a afinação, a percepção musical, a postura e a técnica vocal só terão resultado se o andamento do ensaio, os alunos e o educador estiverem concentrados e dedicados para a aula de canto coral. Autores como Vilson Galvadão de Oliveira (2003), Lacerda e Lacerda (1998) e Teixeira (2008) também destacam a importância destes elementos.

É comum os alunos nessa faixa etária ficarem envergonhados em cantar, principalmente os "coristas de primeira viagem". Observo que há uma relação entre as atitudes propiciadas pela idade na qual se encontram concomitantemente com a motivação do aluno a partir do interesse deste para a aula de canto coral. Acredito que a timidez e a vergonha também sejam fatores que influenciam na aula de canto coral, como destaco no diário acima "eles estavam muito tímidos, alguns só me observavam e não respondiam ao que eu perguntava, ficavam mudos”. Segundo Lacerda e Lacerda (1998), o trabalho com adolescentes exige um cuidado maior, pois estão passando por uma fase de transição entre a

\footnotetext{
${ }^{6}$ Vocalizes são pequenos trechos melódicos que vão sendo transpostos gradualmente para tons ou semitons agudos e graves, criados pelo regente do coral, para trabalhar a articulação, impostação, respiração, afinação e aquecimento vocal, antes do repertório trabalhado no grupo.
} 
infância e a idade adulta, na qual alguns já possuem responsabilidades, porém não conseguem controlar suas emoções e atitudes.

\begin{abstract}
Os adolescentes precisam sentir firmeza da parte dos adultos, como se estes fossem os corrimões onde se vão segurando enquanto crescem. Sentir que os adultos estão seguros a seu lado é muito importante para a sua segurança, embora esperneiem e façam escândalo por não quererem dar o braço a torcer e reconhecer sua necessidade de protecção. (LACERDA; LACERDA, 1998, p. 36).
\end{abstract}

Com isso, os autores ressaltam que o adolescente acaba tentando buscar uma identidade pessoal, a qual se reflete em suas atitudes às vezes tímidas, às vezes rebeldes, às vezes de desânimo ou de grande êxtase, e com isso precisam se sentir seguros com os que estão à sua frente. Por outro lado, Kater (2004) reflete sobre pensar as representações que fazemos hoje, como educadores, e pelas quais constituem-se para o desenvolvimento e na busca por um trabalho musical qualificado. O educador musical, segundo Kater (2004), é “como qualquer professor, presta-se, querendo ou não, como modelo de referência para seus alunos, não só do ponto de vista musical (sua competência técnico-específica, digamos), mas também enquanto pessoa humana que é" (p. 45).

Contextualizando para a aula e o funcionamento do canto coral, início o ensaio com relaxamento corporal, aquecimento vocal, técnica vocal e montagem do repertório. As músicas trabalhadas são de vários estilos musicais, incluindo MPB, folclóricas, latinoamericana, jazz, com acompanhamento de violão, teclado, acordeom e/ou percussão. Eis o dilema:

\begin{abstract}
Muitos forçam para cantar, e não estou sabendo como mostrar-lhes o caminho certo. O fator da mudança vocal em alguns meninos me deixa um pouco aflita, pois não quero que forcem a voz. As gurias, ao contrário, são muito afinadas. Penso que o ensaio por naipes seria uma boa opção, pois tem meninos que são afinados, porém quando cantam no grande grupo acabam se desconcentrando e cantando qualquer coisa (DIÁRIO 04.10.2010).
\end{abstract}

Para Vilson Oliveira (2003), o regente/educador ${ }^{7}$ necessita conhecer, além dos processos musicais, os biofisiológicos, como a mudança vocal, presente em qualquer coro que trabalhe com adolescentes. Segundo o autor, a laringe é versátil, sendo, biologicamente, uma

\footnotetext{
${ }^{7}$ Adaptei a expressão para regente/educador, por acreditar que, em projetos sociais e em situações não formais de ensino de canto, este termo é mais apropriado, visto que minha função neste projeto não compete à regência e ao gestual, mas na experiência da prática coral como educadora musical englobando aspectos culturais, estéticos e musicais.
} 
parte da anatomia na qual se encontram as cordas vocais. Levando em conta estes aspectos, o regente/educador, para conseguir uma versatilidade no processo sonoro, necessita realizar um trabalho intenso de preparação vocal e conscientização destes para melhor resultado vocal. Vilson Oliveira (2003) expõe que, "nesse período, tais práticas provocam uma deficiência na produção vocal, essencialmente, na passagem da região aguda para a grave ou vice-versa, não permitindo que maiores extensões vocais sejam desenvolvidas" (p. 25).

Além disso, fatores culturais são de grande importância quando o assunto é desafinação. Segundo Sobreira (2003), se a afinação pode ser considerada um fator cultural, e não algo fixo e imutável, a desafinação pode seguir os mesmos critérios de avaliação. Assim sendo, para se considerar "alguém desafinado, deve-se levar em consideração o contexto e a cultura em questão" (p. 31). Preocupações sobre afinação e estratégias sobre como mostrarlhes formas mais corretas de cantar e utilizar a voz estiveram presentes ao longo de todo o período em que eu escrevo os diários, e irão persistir. Principalmente, por ser um grupo dentro de um projeto social, que sempre está recebendo novos cantores e percussionistas, pois, de acordo com Vilson Oliveira (2003), os sinais de mudança vocal estarão presentes sempre que trabalharmos com alunos nesta faixa etária. Perguntas sobre se eles estariam forçando a voz e como ensinar-lhes a "pegar" o tom das músicas são vistas no trecho a seguir:

\footnotetext{
Desses, um aluno não conseguia afinar, em alguns momentos sim, mas percebi que ele fazia praticamente uma terça acima do que se deveria tocar. Não sei a forma certa de como dizer isso para o aluno, e também não quero dizer isso a ele, e a nem outro aluno, por enquanto. Então, como primeira opção peço que me escutem, $e$ percebam como cantei, e tento achar com eles a nota inicial, brincando com a voz, pois achando ela, eles conseguem acompanhar a melodia (DIÁRIO 04.05.2011).
}

Tanto na segunda epígrafe quanto nessa há uma ligação referente à escuta musical. Por mais que eu faça diferentes e variados exercícios de vocalizes, utilizando minha própria voz, o teclado e o violão, me pergunto: Será que eles estão ouvindo e percebendo o que cantam? Barros e Lopes (2010) descrevem a importância do "parar para escutar uns aos outros, cultivar a arte do encontro, calar muito, ter paciência e dar-se tempo e espaço" (p. 420). São atitudes que permitem que a aula assuma um lugar de experiência e transformação para o aluno e para o professor:

O aluno, na maior parte das vezes, não está habituado a se perceber, a prestar atenção em e repeti-las, não tem consciência do que está fazendo. Para que o aluno comece a ter essa consciência e possa fazer suas próprias escolhas é preciso que ele 
SALA, H. D.; LURO, A. L. L.

aprenda a se ouvir. O aluno aprende a se ouvir - e ouvir aqui não é só com o ouvido, é perceber o que acontece com seu corpo, como um todo, enquanto canta - à medida que é convidado e estimulado a fazer isso. (BARROS, LOPES, 2010, p. 419).

Como educadora, trata-se de um grande desafio fazer com que as aulas sejam significativas e tenham bons resultados, porém, não posso deixar que minhas aulas se tornem momentos que apenas objetivam afinação e impostação vocal, que são aspectos relevantes para uma boa performance. Não quero torná-los cantores profissionais, mas que possam gostar de cantar e saber cantar da melhor forma, sem colocar em risco a saúde vocal. Pensando assim, após alguns meses de ensaio, iniciei uma aula com os seguintes questionamentos:

\begin{abstract}
Perguntei sobre o repertório, o andamento dos ensaios, o que eles estavam gostando e o que não gostariam que fizesse novamente, como se sentem cantando e o que esperam do coral neste próximo semestre. Alguns falaram que gostariam de aprender músicas de outros estilos como pagode, sertanejo, gaúcho. A maioria dos meninos comentou que preferiam cantar outro repertório, pois não gostaram das músicas do semestre passado. Falaram também que não conseguem cantar e por isso não se sentem à vontade. As meninas falaram que estão gostando das músicas trabalhadas até o momento. Uns esperavam que no coral fossem aprender a cantar as músicas que escutam no dia a dia e não músicas que eles não 'curtem' (DIÁRIO 16.08.2010).
\end{abstract}

Refleti então sobre todas as aulas ministradas até o momento. Alguma vez eu perguntei a eles se estavam satisfeitos com aquele repertório? Se eles gostam de cantar? E o que é cantar para eles? Será que os objetivos que eu tracei para eles são os mesmo que eles traçaram para a aula de canto coral?

Acredito não tê-los deixado livres para expressarem o que estavam sentindo com relação às aulas. Fiquei frustrada ao perceber minha atuação enquanto educadora musical. Na minha visão, eu estava sendo uma professora aberta e que valorizava as opiniões dos alunos. No entanto, eu estava impondo um repertório que eu desejava que eles cantassem, e não o que eles queriam cantar. Segundo Teixeira (2008), para proporcionar aos cantores uma aprendizagem significativa, o regente/educador precisa motivar os alunos a partir dos objetivos do grupo e, para isso, necessita compreender o que eles pretendem com o canto coral. E ainda, desenvolver um repertório composto por músicas que os cantores gostam e que consigam cantar.

Pensando muito em como modificar minha prática, impus-me o desafio de me aproximar mais deles e deixá-los livres para opinarem nas aulas. Modificando a minha 
postura, no decorrer, tornei-me mais flexível na cobrança da afinação, impostação vocal, técnica vocal e no repertório. Não quer dizer que abdiquei destes elementos e da cobrança da qualidade deles, porém, vendo a conexão entre todos os pontos mencionados até o momento deste trabalho, percebi que a flexibilidade deixaria o ensaio mais tênue, agradável e prazeroso. De acordo com o que comento:

Perguntei aos alunos quais instrumentos poderíamos adicionar à música. Cada um foi dando ideias e sugestões. Formamos uma introdução com percussão corporal no ritmo de baião. Depois com o violão fazendo a harmonia, resolvemos incluir o cajon, pandeiro e mais um instrumento com prato (feito por um dos alunos) [...] Essa dinâmica de chamá-los para fazer o arranjo da música junto comigo foi bem aceita e senti neles mais interesse e vontade de cantar. (DIÁRIO 18.10.2011).

Refletindo sobre minha relação com o grupo, passei a conviver mais com eles e a participar das atividades e reuniões da ONG. Nesse interim, percebendo suas características e preferências musicais e das músicas que fazem parte das vivência deles para, aos poucos, incluir outros estilos e gêneros. Nas ocasiões em que dialoguei sobre suas preferências musicais, percebi que, inclusive nas partes técnicas eles me escutavam e tentavam melhorar. Foi então que constatei que somente seria possível resgatá-los para o ensino de canto se eu trabalhasse músicas que fazem parte de suas vidas, como destacam os alunos observando que achavam que iriam trabalhar com "as músicas que escutam no dia a dia e não músicas que eles não “curtem”. Segundo Louro (2008), os conteúdos que são trazidos pelos alunos passam a fazer sentido no momento em que eles e o professor interagem sobre estes conteúdos, possibilitando assim a inclusão destes repertórios/conhecimentos no processo de aprendizagens. Peres (2006) defende que sem dúvida seria desejável modificar o nosso olhar sobre as coisas e modificando o olhar descobrimos que o diálogo "é a condição primeira do conhecimento: descobrir e descobrir-se no Outro" (p. 59).

Independentemente de qual estilo for a música, esta tem sua importância, seu valor cultural e sua representação na vida do apreciador. Segundo Duarte (2009), nas

práticas de escuta musical, o professor se deixa levar junto com seus alunos, por uma viagem de descobertas, nas entrelinhas de cada canção, favorecendo correlações entre a criatividade e a criação de diferentes formas de pensar ou entender o mundo. $\mathrm{O}$ professor não deve se restringir às produções musicais que pertençam aos seus referenciais. A música, seja ela sertaneja, popular, erudita, regional, carrega os valores da cultura que a originou. (p. 120). 
Quando dialoguei com meus alunos notei que além das aulas fluírem mais, o meu olhar para os interesses deles acabou motivando-os para as aulas. Além disso, trazer para a aula de coral as ideias dos alunos mostrou que as suas vivências musicais são tão importantes quanto as minhas experiências. Não busco nesta pesquisa criticar ou avaliar se estilos musicais como pagode, sertanejo, gaúcho, citados pelos alunos, se devem fazer parte do ensino de música ou não, mas que aproveitar o gosto musical do aluno como estratégia de ensino foi a forma que encontrei de trazê-los para a aula de canto coral.

Com o projeto social, mesmo após a monografia, continuei vivenciando desafios iguais aos aqui relatado. A cada ensaio, tenho uma nova reflexão, uma situação diferente, e vejo o canto como algo que está contribuindo dentro do grupo de percussão.

\begin{abstract}
No ensaio de hoje, parei um instante para refletir o que levou os alunos a estarem ali, enquanto todos se ajeitavam em roda, para o começo da aula. Nossa... era um dia de uma garoa fina no bairro Camobi, uma tarde de sábado cinzenta, e eles estavam presentes (cerca de 17 crianças) todos ali, na minha frente, esperando o início do ensaio. O que levou eles a saírem de suas casas, num final de semana para um ensaio de coral? Me dei conta do significado que talvez as aulas atuais estão proporcionando a eles, as novas letras e melodias, das músicas estavam causando no corpo e mente de cada um deles algo bom... Semente do Amanhã... foi a música pedida por alguns alunos no ensaio de ontem (sexta-feira) para ser trabalhada no sábado... comecei o ensaio... (DIÁRIO 16.06.2012)
\end{abstract}

Lembrando de 2010, lembrei como foram difíceis os ensaios. Antes, eles não queriam estar ali, nem queriam cantar, nem se apresentar; em 2012 com esse grupo, a ideia foi diferente, eles mostraram-se mais comprometidos, esforçados, sempre pediam por apresentações. Eu retomo a pergunta $O$ que os levou a saírem de suas casas, num final de semana para um ensaio de coral? Não saberei responder, e penso sobre a importância de ter perseverado e mudado minha postura como professora, para motivá-los para a aula de coral. $\mathrm{O}$ ato de rever meus caminhos através da escrita influenciou para o sucesso das aulas atuais. Outra situação relato a seguir:

E iniciou a apresentação... a interação deles em cima do palco foi surpreendente, além da sincronia com todos os instrumentos que estavam acompanhando o coral como a bateria, o pandeiro, o tambor, os chocalhos, os violões, a gaita de boca... (Diário 12.07.2012)

Assim como narro nesse trecho vejo uma mudança entre eles, quando estão na aula e nas apresentações, senti maior coleguismo entre o grupo, a vontade de cantar, o resultado dos ensaios durante o ano com sua interação e o repertório formado. Trata-se de um conjunto de 
estratégias e trabalho que fizeram a diferença numa simples apresentação. Situações como a mudança vocal, timidez em cantar, afinação, indisciplina, clientela flutuante, apresentações inesperadas, sempre se farão presentes neste ambiente de trabalho. Isso tudo é projeto social, fato que eu demorei a perceber. Com certeza, esses dilemas fazem e acontecem em outras instituições/projetos que trabalham com adolescentes e com o canto coral.

Em meio a todas estas questões e reflexões, constituo-me como professora de canto coral; encantei-me com o ensino em um projeto social, vivi angústias que me paralisavam e que a todo o momento me levaram a questionar sobre minha prática e minha atitude como professora. Atualmente, por mudanças pessoais e de mobilidade, não ministro mais aulas no projeto, na qual foi uma escolha um tanto dolorosa, porém o canto coral passou a se tornar grupo vocal e hoje é comandado por uma das alunas que mais se destacou do projeto, e que esta a frente de ensaios e apresentações.

Acredito ter evoluído no momento em que aceitei meus erros, mediante minhas próprias reflexões, por meio das quais iniciei uma nova forma de ministrar as aulas. Apropriome das palavras de Peres (2006), que nos remete a pensar sobre a importância durante a formação do(a) professor(a), de trabalharmos com as nossas incertezas e com as nossas invisibilidades, para que a partir dessas experiências possamos exercitar nossa sensibilidade como professores para atendermos à realidade na qual estamos trabalhando e atuando:

Professor(a) formador(a) e aprendizes de professores(as) revisitam suas potencialidades, recriando "novas" modalidades de ir se fazendo professora(r). A questão exposta nos faz refletir o quão importante é refazermos alguns dos caminhos dos nossos porões interiores, sobretudo procurarmos, dentro de nós mesmos, onde e como as teorias ressoarão no futuro fazer pedagógico. A indagação, a incessante busca pela pergunta, a lida com os desassossegos, poderão nos levar a caminhos e práticas singulares e significativas. (PERES, 2006, p. 56).

Assim como Vilson Oliveira (2003) esclarece que possuímos uma representação do que é um professor, uma escola, uma aula, e que estas imagens se configuram em saberes construídos ao longo de nossas histórias de vida. Modificar aquilo que estamos acostumados a fazer é algo muito difícil, mas precisamos adentrar na memória de nossas trajetórias de vida, as quais são refletidas em nossa prática. De antemão esclareço que, sem uma autorreflexão não haveria mudança na forma de ensino e nem do meu pensamento. Josso (2004) esclarece que a formação como processo de mudança requer uma escolha, dependendo de cada geração ou espaço em que a educação está inserida. Segundo ela, para que isso ocorra, é necessário 
SALA, H. D; LURO, A. L. L.

preservar, conservar, esquecer, abandonar, ou inventar novas situações que envolvem o cotidiano, o espaço sociocultural, as resistências dos envolvidos e os próprios hábitos, tanto dos professores quanto dos alunos. Nesse caso, submergem o lugar em que o educador leciona, para que este consiga interagir e despertar-se para o querer aprender, por meio da mudança.

\section{CONSIDERAÇÕES FINAIS}

Uma pesquisa sob este tema aproxima questões da Educação Musical de autores da área de Educação como Zabalza e Oliveira, e propõe também uma aproximação dos modos como o professor em formação passa a ler a si mesmo, ou mesmo metaforicamente tem uma escuta de si em uma linguagem verbal através dos diários de aula. Além disso, influencia no modo como os alunos de canto coral podem tornar-se mais atentos para ouvir a si e aos outros, em busca de uma afinação possível. Ao refletir nos diários de aula, pude, através dessa ferramenta, descobrir o quanto me assemelhava a meus antigos professores e o quanto a minha formação acadêmica musical, algumas vezes, se distanciava das realidades musicais vividas por meus alunos. Por outro lado, percebo que tais questões centradas em aspectos metodológicos do meu modo de ensinar se aproximam também de um dos meus principais dilemas como regente/educadora, resumidos na pergunta: “Como fazê-los afinar?". Esta aproximação se dá na medida em que a minha narrativa de si contribui para a moldagem da minha identidade de professora, da mesma forma em que paro para ouvir os outros participantes do processo identitário do ser músico dos meus alunos.

Nesta direção, a presente pesquisa traça uma possível aproximação entre questões de metodologia de ensino de uma forma geral e questões específicas do ensino da música. Tais questões, ao contribuírem com minha reflexão de professora, podem influenciar também nos debates da área de Educação Musical e da área de Educação. Especialmente, sobre a formação de professores nesta área e de outras áreas do conhecimento, na medida em que discuto sobre a "narrativa de si" como possibilidade de reflexão, no sentido da metáfora ótica de se olhar no espelho enquanto movimento, utilizando os diários de aula como metodologia.

THE DAILY CLASSROOM AS A SPACE FOR NARRATIVE SELF INSIDE OF CORAL SINGING LESSONS IN A SOCIAL PROJECT 


\begin{abstract}
This article shows a reflection on the teaching of music, highlighting issues related to social projects. The musical educator narrates their dilemmas, written between April 2010 and December 2012, as a teacher of choral singing for teenager in a social project, whose methodology "own narrative" and "self-narratives" (OLIVEIRA, 2009) that is reflected through the diaries of class (ZABALZA, 2004). The study aims to investigate the role of the teacher and the ways these in their teaching, using the tool of the daily class as a place to "write itself" and "narrative of oneself", promoting reflections in order to understand and modify their practices and thus shape their professional identity. The text also examines the conflicts present in practice in social projects (KATER, 2004; KLEBER, 2006, 2008;); questions the practice of choral singing (AMATO, 2007; TEIXEIRA, 2008), recounts classroom situations, focusing on professional identities involved in changing practices for achieving teenagers to class percussionists of choral singing.
\end{abstract}

Keywords: Music Education; Social Project; Choral singing; Narratives self; Autobiography

\title{
DIARIO DE CLASE COMO ESPACIO PARA (AUTO) NARRATIVA DE CLASES EN LA ESQUINA DE CORAL EN UN PROYECTO SOCIAL
}

\section{Resumen}

En este artículo se presenta una reflexión sobre la enseñanza de la música, destacando los temas relacionados con los proyectos sociales y el canto coral. En ella, el educador musical narra sus dilemas como profesor de canto coral para adolescentes escritas entre abril de 2010 y diciembre de 2012, en un proyecto social, cuya metodología "autonarrativa" y "autonarrativas" (OLIVEIRA, 2009), reflejado tanto en la lección diaria (ZABALZA, 2004). Presente estudio tiene como objetivo investigar el papel del profesor y las formas en que estos en su enseñanza, con la función en la lección diaria como un lugar para "escribir en sí" y "narrativa de uno mismo", promoviendo reflexiones para comprender y modificar sus prácticas y por lo tanto dan forma a su identidad profesional. También se examinan los 
conflictos que se producen en la práctica en los proyectos sociales (KATER, 2004; KLEBER, 2006; 2008); discute la práctica del canto coral (AMATO, 2007; TEIXEIRA, 2008), narra situaciones en el aula, centrándose en las identidades profesionales que participan en cambios en las prácticas de conquistar el bateristas adolescente clase de canto coral.

Palabras clave: Educación musical; Proyecto social; Canto coral; Propias narraciones; Autobiografía

\section{REFERÊNCIAS}

AMATO, Rita Fucci. O canto coral como prática sócio-cultural e educativo-musical. Opus, Goiânia, v. 13, n. 1, 2007, p. 75-96.

BORBA, Marcelo Barros de; BECK, Renata Machado; LOURO, Ana Lúcia de Marques Hettwer. Docência no ensino superior de música: formação e experiência a partir de três trabalhos investigativos IN: Anais IX Seminário Anped Sul. Caxias do Sul: Universidade de Caxias do Sul, 2012, p. 1 - 16

BARROS, Maria de Fátima Estelita, LOPES, Sara Pereira. A Pedagogia do canto na perspectiva da experiência. Anais do XX Congresso da ANPPOM. Florianópolis, SC. 2010. p. 416 Disponível em: http://www.anppom.com.br/anais/anaiscongresso_anppom_2010/ANAIS_do_CONGRESSO ANPPON_2010.pdf. Acesso em: 12 setembro. 2013.

CAMPOS, Ana Yara. Um Olhar para o Canto Coral - In: Balaio Cultural, Ano 3, Ed. 23, Ourinhos: SP. 2009 (reportagem).

CAMPOS, Ana Yara; CAIADO, Katia Regina Moreno. Coro universitário: uma reflexão a partir da história do Coral Universitário da PUC-Campinas, de 1965 a 2004. Revista da ABEM, Porto Alegre: Associação Brasileira de Educação Musical, vol. 17, Mar. 2007.

DUARTE, Rosangela. Makunaimando e o Hino de Roraima: contexto de criação/recepção. In: BEYER, E.; KEBACH, P (Org.) Pedagogia da música - experiências de apreciação musical. Porto Alegre: Ed. Mediação. 2009.

EGGERT, Edla. Quem pesquisa se pesquisa? Uma provocação a fim de criar um espaço especulativo do ato investigativo. In: ABRAHÃO, Maria Helena Menna Barreto. A Aventura (Auto)Biográfica - Teoria e Empiria. Porto Alegre: EDIPUC, 2004. p. 549-584.

FONTERRADA, Marisa Trench de Oliveira. De tramas $e$ fios: um ensaio sobre música e educação. $2^{\text {a }}$ Ed. São Paulo: Editora Unesp; Rio de Janeiro: Funarte, 2008.

KATER, Carlos. O que podemos esperar da educação musical em projetos de ação social. Revista da ABEM, Porto Alegre, vol. 10, Mar. 2004. Disponível em: 
http://www.abemeducacaomusical.org.br/Masters/revista10/revista10_completa.pdf. Acesso em: 14 maio. 2014.

KLEBER, M. O. A prática de educação musical em ONGs: dois estudos de caso no contexto urbano brasileiro. Tese (Doutorado em Música), Instituto de Artes, Universidade Federal do Rio Grande do Sul. Porto Alegre, 2006.

.Projetos sociais e educação musical. In: SOUZA, Jusamara (Org.) Aprender e ensinar música no cotidiano. Porto Alegre: Ed. Sulina, 2008.

JOSSO, Marie-Christine. Experiências de Vida e Formação. São Paulo: Cortez, 2004.

LACERDA, Catarina Augusta de Oliveira Pasin de; LACERDA, Milton Paulo de. Adolescência: problema, mito ou desafio? Petrópolis, RJ: Vozes, 1998.

LOURO, Ana Lúcia. Narrativas de docentes universitários-professores de instrumento sobre mídia: da relação "um para um" ao "grande link". In: SOUZA, Jusamara. Aprender e Ensinar Música no Cotidiano. Porto Alegre: Sulina, 2008.

NOGUEIRA, Paulo. A Entrevista Narrativa: contexto, temporalidade, experiência. In: NOGUEIRA, Paulo. A escrita, os escritores e a relação com a escrita. Para uma abordagem narrativa e biográfica em Educação. Berlin: Schaltungsdienst Lange o.H.G. 2015. p. 322-366

OLIVEIRA, V. M. F. A Escrita Como Dispositivo Na Formação De Professores. In: 17º Congresso de Leitura do Brasil - COLE: É preciso transver o mundo, 2009, Campinas: Unicamp, FE; ALB, 2009. p. 1- 24.

Narrativas e Saberes Docentes. Ijuí: Ed. Unijuí, 2006.

OLIVEIRA, Vilson Gavaldão de. Coro Juvenil: O Desafio para regentes e cantores. In: Canto Coral - publicação oficial da Associação Brasileira de Regentes de Coros. Ano II, nº 2, 2003.

PERES, Lúcia Maria Vaz. Os caminhos e os desassossegos no tornar-se professor(a)... In: OLIVEIRA, Valeska Fortes de. Narrativas e Saberes Docentes. Unijuí: Ijuí. 2006.

SANTOS, Marco Antonio Carvalho. Educação musical na escola e nos projetos comunitários $e$ sociais. Revista da ABEM, Porto Alegre, vol. 12, Mar. 2005. Disponível em: http://abemeducacaomusical.com.br/revista_abem/ed12/revista12_completa.pdf. Acesso em: 14 maio. 2015.

SOBREIRA, Silvia Garcia. Desafinação vocal. Rio de Janeiro: 2003.

SOUZA, Jusamara. Música, cotidiano e educação. Porto Alegre: Sulina, 2000. Aprender e ensinar música no cotidiano. Porto Alegre: Sulina, 2008. p. 259 - 283 
SALA, H. D.; LURO, A. L. L.

TEIXEIRA, Lúcia. Espaços de atuação e formação de regentes corais: os desafios do contexto. In: SOUZA, Jusamara. Aprender e ensinar música no cotidiano. Porto Alegre: Sulina, 2008.

ZABALZA, Miguel A. Diários de aula: um instrumento de pesquisa e desenvolvimento profissional. Porto Alegre: Artmed, 2004.

Data de recebimento: 26/11/2013

Data de aceite: 24/03/2015 